Nig. J. Pure \& Appl. Sci. Vol. 34 (Issue 2, 2021)
e-ISSN 2756-4045
Life Sciences, Univ. of Ilorin, Nigeria
www.njpas.com.ng

\title{
Antiplasmodial Activities of Some Locally Prepared Herbs Against Plasmodium falciparum Obtained from Asymptomatic School Children in Zaria, Kaduna State, Nigeria
}

\author{
*Balogun, Islamiat D., Inabo, Helen I. and Ella, Elijah E.
}

Department of Microbiology, Ahmadu Bello University, Zaria, Kaduna State, Nigeria.

Date Received: 29-06-2021

Date Accepted: 12-09-2021

DOI: https://doi.org/10.48198/NJPAS/21.A18

\begin{abstract}
The efficacy of current or any intended antimalarial can only be resolute by cultivation and susceptibility studies. The aim of this research was to cultivate Plasmodium falciparum in vitro and comparing the antiplasmodial effects of standard antimalarial medications including herbaceous preparation. Asymptomatic pupils attending some schools in Zaria, Kaduna state, Nigeria were recruited into this research and blood samples were collected from them. Microscopy was done after thin and thick blood films were prepared and stained. The antiplasmodial activities of antimalarial drugs as well as herbal preparation were determined after the successful culturing of red blood cells in the Jatropha curcas medium. The phytochemical constituents of the herbs that made up the concoction were determined. The incidence of asymptomatic Plasmodium infection amongst school kids was $17.5 \%$. There was no statistical association of location, gender and age with the obtained prevalence. Presence of alkaloids was observed in every plant screened while the same was also observed for tannins except in Enantia chloranta. Steroids and phlobatanins were observed in Citrus aurantifolia while there was presence of saponins in all the plant extracts except Cymbopogbon citratus. All the plants except Enantia chloranta contained flavonoids. There was presence of terpenoids in all screened plants except Azadirachta indica and Cymbopogbon citratus while cardiac glycosides were found in every plant except Magnifera indica and Enantia chloranta. Results obtained from the in vitro cultivation of the Plasmodium falciparum with Athemether/lumefanthrine, amodiaquine and herbal concoction showed average percentage parasite inhibition of $80 \%, 37.8 \%$ and $38.6 \%$ respectively. This implies that Arthemether/lumefanthrine was capable of inhibiting the growth of the parasite best. The herbal concoction also inhibited growth (38.6\% inhibition). There is need for additional investigation on a wider variety of plants to explore their antiplasmodial activities since there is evidence that it works, and it is quite available and affordable.
\end{abstract}

Keywords: Prevalence, Plasmodium falciparum, Phytochemical, Herbal Concoction, Jatropha curcas

Corresponding Author: Balogun, I.D.

Department of Microbiology, Ahmadu Bello University, Zaria, Kaduna State, Nigeria. Phone: +2347064306670; Email: damilolabalogun08@gmail.com 


\section{Introduction}

Malaria is caused by infection with protozoan parasites of the Plasmodium species. Plasmodium falciparum is widespread in Africa while $P$. vivax, Page | 4102 P. ovale, and P. malariae infections are uncommon and geographically restricted (Howes et al., 2015). The transmission of the parasites is by Anopheles mosquitoes with An. gambiae sensustricto, An. funestus, and An. arabiensis being the foremost common in Africa (Sinka et al., 2010). Malaria is endemic in large parts of Sub-Saharan Africa. It had been estimated in 2017 that 219 million cases of malaria occur worldwide and $92 \%$ of worldwide cases were within the African region (WHO, 2020). Asymptomatic Plasmodium parasitaemia is Plasmodium parasitaemia of any density, within the absence of fever or other acute symptoms in individuals who haven't received recent antimalarial treatment. It's been identified as a reservoir for malaria transmission also as a precursor within the progression to symptomatic disease. The clinical consequences of asymptomatic Plasmodium parasitaemia in children aren't fully understood and it's generally assumed that in endemic areas, asymptomatic parasitaemia results from the event of partial immunity (Njama-Meya et al., 2004).

The methods for cultivation of the erythrocytic stages of $P$. falciparum reported by Trager and Jensen (1976) are usefully applied in nearly all aspects of research on malaria; chemotherapy, drug resistance, immunology and vaccine development. Therefore, species that infect humans are cultured in vitro, of those four Plasmodium species; $P$. falciparum remains the sole species that all stages are cultured. The commercially prepared culture Rosewell Park Memorial Institute (RPMI) 1640 medium to which serum and erythrocytes are added for cultivation of Plasmodium falciparum species were found to be less commonly used in Nigeria probably because of its cost and storage problem. (Nassar et al., 2014). It's therefore necessary to hunt optional methods for cultivating Plasmodium spp to avoid the aforementioned problem of
(RPMI). This led to the utilization of Jatropha plant extract medium for cultivation. Jatropha curcas, a drought resistant large shrub belongs to the genus Euphorbiaceae and has oil producing seeds (Openshaw, 2000).

Herbal plants are medicinal plants which are useful to humans in combating diseases from the dawn of civilization. In this study, the antiplasmodial activities of a concoction prepared from neem, Magnifera indica, Citrus aurantiifolia, Cymbopogbon citratus and Enantia chlorantha leaf extracts in various concentrations were determined. The aim of this research hence is to research the antiplasmodial activities and phytochemical constituents of some locally sold herbs against Plasmodium falciparum obtained from school children in Zaria, Kaduna state.

\section{Materials and Methods \\ Study Area}

The study area was Zaria, Kaduna state, Nigeria. Zaria, a major city in Kaduna state in Northern Nigeria is found on latitude $11^{\circ} 04^{\prime} \mathrm{N}$ and longitude $7^{\circ} 42^{\prime} \mathrm{E}$ and is an ancient city in Kaduna state. It is a largely heterogenous city with a population of about 1,490,000 of individuals drawn from different ethnic mix during where Hausa and Fulani predominate. It is the gateway to many states within the north and thus provides the unique and multicultural population ideal for the conduct of the study (Oladimeji and Ojiboo, 2012).

\section{Study Population}

The study was conducted among school children between the ages of 2-15 years attending schools selected randomly across two government areas (LGAs) in Zaria metropolis.

\section{Study Design}

A cross sectional, school-based study where equal numbers of samples were obtained from children with consenting parents attending selected schools, employing a simple randomized sampling technique. The study population was drawn from 
five schools. Two of the faculties, LEA primary school Wusasa and Ahmad Gyallesu primary school are located in Zaria LGA while LGEA primary school Kwangila, LEA primary school Zango, and UBE Layin-Zomo are situated in

Page | 4103 Sabon-Gari LGA. These schools serve an outsized population of youngsters seeking knowledge. Children that weren't within the defined age group, showed symptoms of malaria like chills and fever also as those whose parents declined consent were excluded from the research. Ethical approval was granted by Kaduna State Ministry of Health and Human Services ethics board (REFMOH/ADM/744/VOL.1/795).

\section{Determination of Sample Size}

The sample size was arrived at by means of the equation by Sarmukaddam and Gerrard (2006) and a prevalence of $14.1 \%$ (Inabo and Umaru, 2011) at $95 \%$ confidence interval

$\mathrm{n}=\mathrm{Z}^{2} \mathrm{Pq} / \mathrm{L}^{2}=1.96^{2} \times 0.141 \times 0.859 / 0.05^{2}=$ $0.4512 / 0.0025=180.48 \sim 180$ samples

The calculated minimum size was 180; however, 200 blood samples were collected for the assay.

\section{Collection of Samples}

Venous blood samples were collected from 200 children aseptically into Ethylene Diamine Tetra ethanoic acid (EDTA) vacutainer tubes through venipuncture with the help of professional and authorized medical personnel. The samples were transported in cold packs to the Department of Microbiology, Ahmadu Bello University Zaria for analysis.

\section{Preparation and examination of thick and thin films for trophozoites and parasite density}

Thin and Thick blood films were prepared and stained with 5\% Giemsa stain for the microscopic examination of malaria parasites as described by (Cheesbrough, 2000). Thin film was for the identification of trophozoites and parasite species, whilst thick film showed parasite density. Parasite density per microliter of blood (parasitemia) was derived from the thick film taking the amount of leucocytes per microliter of blood as 8000 and expressed as follows:

Parasite density $(\mu 1)=\frac{\text { Parasite count } x 8000}{\text { Number of WBCs counted (2 09) }}$

\section{Phytochemical Analyses}

Chemical tests were conducted for the occurrence of tannins, saponins, phlobatanins, flavonoids, steroids, terpenoids, cardiac glycosides and alkaloids on the aqueous extract as well as on the dry milled specimen using set procedures to spot the constituents as described by Sofowara (1993), Trease and Evans(1989) and Harborne (1973). Preparation of Jatropha curcas medium. Leaves of Jatropha curcas were obtained from Ahmadu Bello University, main campus, Zaria, Nigeria. These were taxonomically identified and authenticated with authentication number (ABU 01911) by a Taxonomist within the Department of Plant Science, Ahmadu Bello University Zaria, Kaduna state, Nigeria. The Jatropha curcas medium was constituted containing $10 \mathrm{ml}$ of the Jatropha curcas leaf extract, $20 \mathrm{mls}$ of water, $2 \mathrm{mls}$ of a $0.2 \mathrm{~g} / \mathrm{ml}$ glucose solution, $1 \mathrm{ml}$ saline and $1 \mathrm{ml}$ PBS 1X. To the medium was also added $12 \mathrm{ml}$ of liver extract, $5 \mathrm{ml}$ of $10 \%$ human serum, $0.2 \mathrm{ml}$ uninfected human red blood cells as well as $15 \mu \mathrm{l}$ Gentamicin. The $\mathrm{pH}$ of the new medium was adjusted to $7.4 \pm 0.2$ using $\mathrm{NaHCO} 3$ solution $(0.002 \mathrm{~g} / \mathrm{ml})$. The fresh medium was stored at $-21^{\circ} \mathrm{C}$ (Nassar et al., 2014).

\section{In-vitro Assay for antiplasmodial activity of locally made concoction (agbo)}

Ingredients used for the locally made concoction includes yellow wood (Enantia chlorantha) bark, lime leaves (Citrus aurantifolia), lemon grass (Cymbopogon citratus), mango (Magnifera indica) leaves, and neem leaves (Azadirachta indica) with authentication numbers (ABU 01846), (ABU 01440), (ABU 06899), (ABU 01944) and (ABU $900151)$ respectively. Each plant was dehydrated in 
shade, chopped and milled to a fine powder. A hot water infusion $(10 \mathrm{~g}$ in $100 \mathrm{ml}$ hot water) was constituted and the solution filtered through Whatman paper No 1 . The extracts $(100 \mu 1$ at $10 \mathrm{mg} / \mathrm{ml}$ ) were serially diluted with sterile water

Page | 4104 and dispensed into the 96 well microtitre plate (Ahmad et al., 2014).

\section{Preparation of Drug and Dosing of the Culture Plate Wells}

Stock solutions of Arthemether/Lumenfanthrine as well as Amodiaquine were prepared in $100 \%$ ethanol. These solutions were filtered with $0.22 \mu \mathrm{m}$ membrane filter (Millipore) aseptically and further dilution of the drug with ethanol was made to get concentrations $0.2,0.4,0.8,1.6,3.2 \mu \mathrm{mol} / \mathrm{ml}$ (Jensen and Trager, 1980). The diluted drugs $(10 \mu \mathrm{l}$ of each) were dispensed in sterile flat bottomed microtitre plate allowing the ethanol to evaporate while the powdered form adhered to the bottom of the plate. For every preparation, a fresh microtitre plate was used. The 96-well micro titre plate consisted of 8 rows (A-F), where Row A was drug free while row $\mathrm{B}-\mathrm{F}$ had various drug concentrations (Basco, 2007).

\section{Examination of Post culture Blood slides and determination of IC50}

After incubation, for 36 hours, microtiter plate was placed in a semi vertical position about $\left(45^{\circ}\right.$ inclined) for 30 minutes. The supernatant was removed, thick blood film made from each well; air-dried, stained with 5\% Giemsa and observed microscopically. Parasite growth was counted in 10 microscopic fields, the average calculated and parasite density determined. The percentage inhibitory concentration was calculated using the formula: (Ngemenya et al., 2006).

Percentage inhibition $=100-$

$\frac{\text { Number of schizont in test wells }}{\text { Number of schizont in control well }}$ X 100
The IC50 values, concentration required to inhibit parasite growth by $50 \%$ decided by linear interpolation from the parasite growth inhibition curves (concentration versus percent inhibition) derived from each parasite-extract interaction (Mustofa et al., 2007).

\section{Data analysis}

The data obtained were analyzed with SPSS (statistical package for social sciences) version 2.0 software program. Pearson's chi-square $\chi 2$ was employed to work out association of variables set significance at $95 \%$ confidence interval and $\mathrm{P}<0.05$ was considered insignificant. Means of parametric variables were analyzed using student $t$ tests.

\section{Results}

The results showed that 35 children representing a prevalence of $17.5 \%$ were positive for Plasmodium falciparum. The prevalence observed among children from LEA Primary school Zango, was $27.5 \%(11 / 40)$ which was the highest, while those that attended LEA Primary School Wusasa had the least prevalence of $12.5 \%$ and this variation was not statistically significant $\left(\chi^{2}=600.000^{\mathrm{a}}, \quad \mathrm{p}<0.05\right)$ (Table 1).

Children between the ages of 6-10 had the highest prevalence of $20 \%(17 / 85)$ while those between the ages $11-15$ had the least prevalence of $15.2 \%$. This variation also had no statistical significance $\left(\chi^{2}=400.000^{\mathrm{a}}, \mathrm{p}<0.05\right) \quad($ Table 2). Furthermore, Plasmodium parasitaemia among males and females was almost the same as a prevalence of $17.3 \%$ (18/104) was obtained; while $17.7 \%$ of the females tested were positive (Table 2).

Alkaloids were present in all the plant extracts; tannins were present in all except in Enantia chloranta. Phlobatanins and steroids were only present in Citrus aurantifolia. Saponins were present in all the plant extracts except Cymbopogbon citratus while flavonoids were present in all the plants except Enantia chloranta. Terpenoids were present in all except Azadirachta 
indica and Cymbopogbon citratus while cardiac glycosides were present in all except Magnifera indica and Enantia chloranta.(Table 3).

The $\mathrm{IC}_{50}$ value of Arthemether/Lumenfantrine, Page | 4105 Amodiaquine and Herbal concoction and 2.3, 7.1 and $4.4 \mathrm{nM}$ were obtained respectively (Table 4).

The effect of Arthemether/Lumenfantrine on Plasmodium falciparum showed average parasite densities of 500, 156.25, 0, 125, 93.75 and 125 parasites per $\mathrm{ml}$ (Fig 1) and parasite inhibition of $68.75 \%, 100 \%, 75 \%, 81.25 \%$ and $75 \%$ (Fig 2). The effect of Amodiaquine on Plasmodium falciparum showed average parasite densities of $1812.5,750$, $1125,1156.25,1450.75$ and 1156.25 parasites per $\mathrm{ml}$ (Fig 1) and percentage inhibition of $59 \%, 38 \%$, $36 \%, 20 \%$ and $36 \%$ (Fig 4 ).
The antiplasmodial efficacy of the locally sold herbs (agbo) which is a concoction of Azadirachta indica, Magnifera indica, Citrus aurantifolia, Cymbopogon citratus, and Enantia chlorantha was also assessed over varying concentrations of 0.2 , 04, 0.8, 1.6 and $3.2 \mu \mathrm{g} / \mathrm{ml}$ and average parasite densities of 2000, 1281.25, 1343.75, 1437.5 and 758 parasites per $\mathrm{ml}$ (Fig 1) and percentage inhibition of $36 \%, 33 \%, 33 \%, 29 \%$ and $62 \%$ respectively (Fig 5).

Table 1: Distribution of Plasmodium falciparum infection among apparently healthy school children in relation to schools in Zaria, Kaduna state.

\begin{tabular}{ccccc}
\hline School & $\begin{array}{c}\text { Number } \\
\text { examined }\end{array}$ & $\begin{array}{c}\text { Number } \\
\text { Positive (\%) }\end{array}$ & Chi-square & p-value \\
\hline LPSW & 40 & $5(12.5)$ & $600.000^{\mathrm{a}}$ & 0.000 \\
AGPSZ & 40 & $6(15)$ & & \\
LPSK & 40 & $7(17.5)$ & & \\
LPSZ & 40 & $11(27.5)$ & & \\
UBELZ & 40 & $6(15)$ & & \\
Total & 200 & 35 & & \\
\hline
\end{tabular}

Key: $\mathrm{p}<0.05=$ No significant association. LPSW: LEA Primary School Wusasa; AGPSZ: Ahmad Gyallesu Primary School Zaria; LPSK: LEAPrimary School Kwangila; LPSZ: LEA Primary School ZangoUBELZ: UBE Layin Zomo

Table 2: Distribution of Plasmodium falciparum infection among apparently healthy school children in relation to age and sex in Zaria, Kaduna state

\begin{tabular}{ccccc}
\hline Host Variable & $\begin{array}{c}\text { Number } \\
\text { examined }\end{array}$ & $\begin{array}{c}\text { Number } \\
\text { positive (\%) }\end{array}$ & Chi-square & p-value \\
\hline Age (years) & & & & \\
$2-5$ & 69 & $11(15.9)$ & $400.000^{\mathrm{a}}$ & 0.000 \\
$6-10$ & 85 & $17(20)$ & & \\
$11-15$ & 46 & $7(15.2)$ & & \\
Total & 200 & 35 & & \\
Sex & & & & \\
Females & 96 & $17(17.7)$ & $200.000^{\mathrm{a}}$ & \\
Males & 104 & $18(17.3)$ & & \\
Total & 200 & 35 & & \\
\hline
\end{tabular}

Key: $\mathrm{p}<0.05=$ No significant association. 
Table 3: Phytochemical Constituents of Selected plants

\begin{tabular}{cccccc}
\hline $\begin{array}{c}\text { Phytochemical } \\
\text { Constituent }\end{array}$ & $\begin{array}{c}\text { Azadirachta } \\
\text { indica }\end{array}$ & $\begin{array}{c}\text { Magnifera } \\
\text { indica }\end{array}$ & $\begin{array}{c}\text { Citrus } \\
\text { aurantifolia }\end{array}$ & $\begin{array}{c}\text { Cymbopogbon } \\
\text { citratus }\end{array}$ & $\begin{array}{c}\text { Enantia } \\
\text { chloranta }\end{array}$ \\
\hline Tannins & + & + & + & + & - \\
Phlobatanins & - & - & + & - & - \\
Saponins & + & + & + & - & + \\
Flavonoids & + & - & + & + & - \\
Steroids & + & - & + & - & - \\
Terpenoids & - & - & + & - \\
Cardiac & + & & + & + & + \\
Glycosides & & & + & &
\end{tabular}

Table 4: In vitro Susceptibility of Plasmodium falciparum isolates to antimalarial drugs and herbal concoction

\begin{tabular}{cc}
\hline Drug & IC $_{\mathbf{5 0}} \mathbf{n M}$ \\
\hline Arthemether/ Lumefanthrine & 2.3 \\
Amodiaquine & 7.1 \\
Herbal Concoction & 4.4 \\
\hline
\end{tabular}

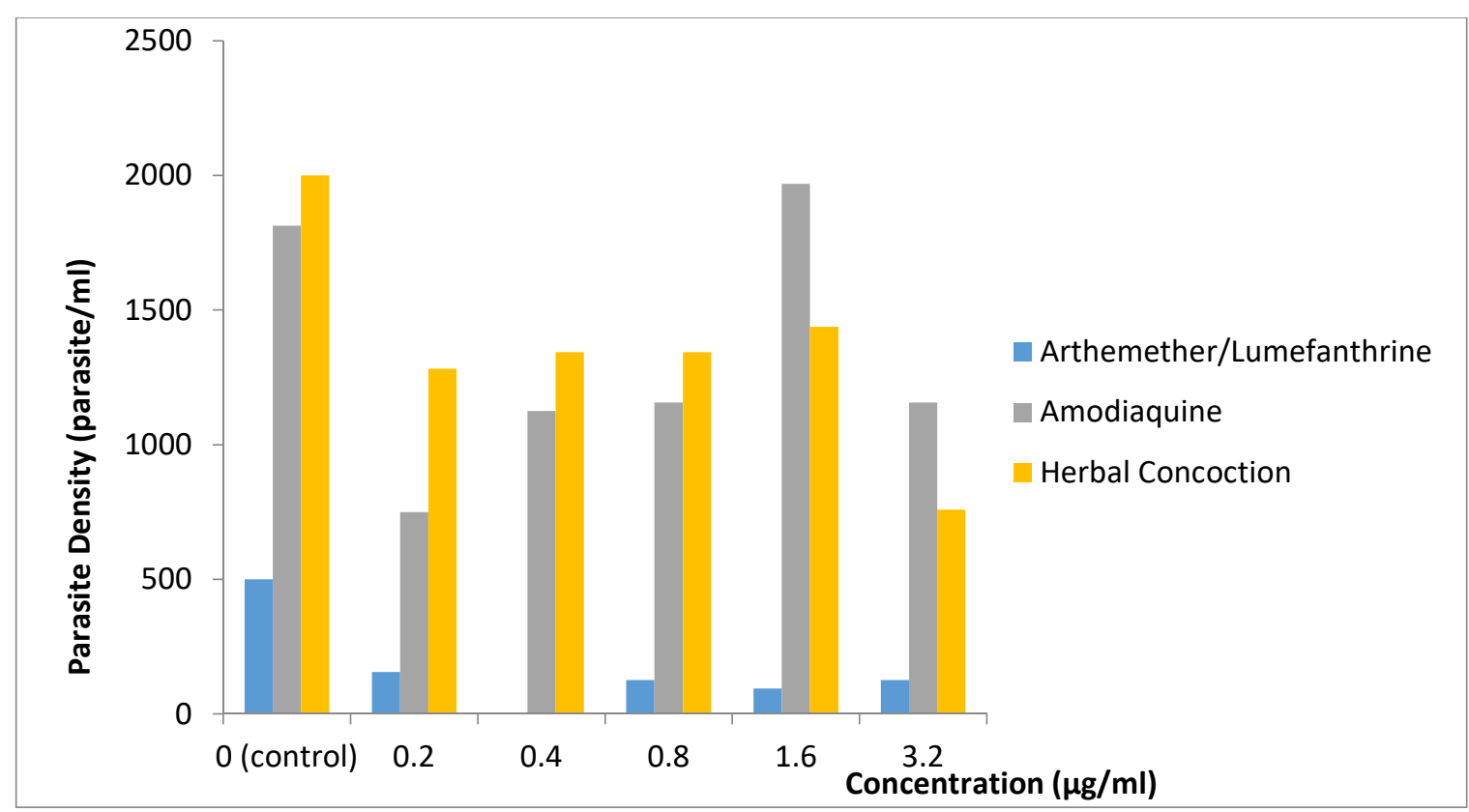

Fig 1: Parasite density of Plasmodium falciparum after cultivation on Jatropha curcas leaf extract medium and inoculation with Arthermether/Lumefanthrine, Amodiaquine and Herbal concoction. 


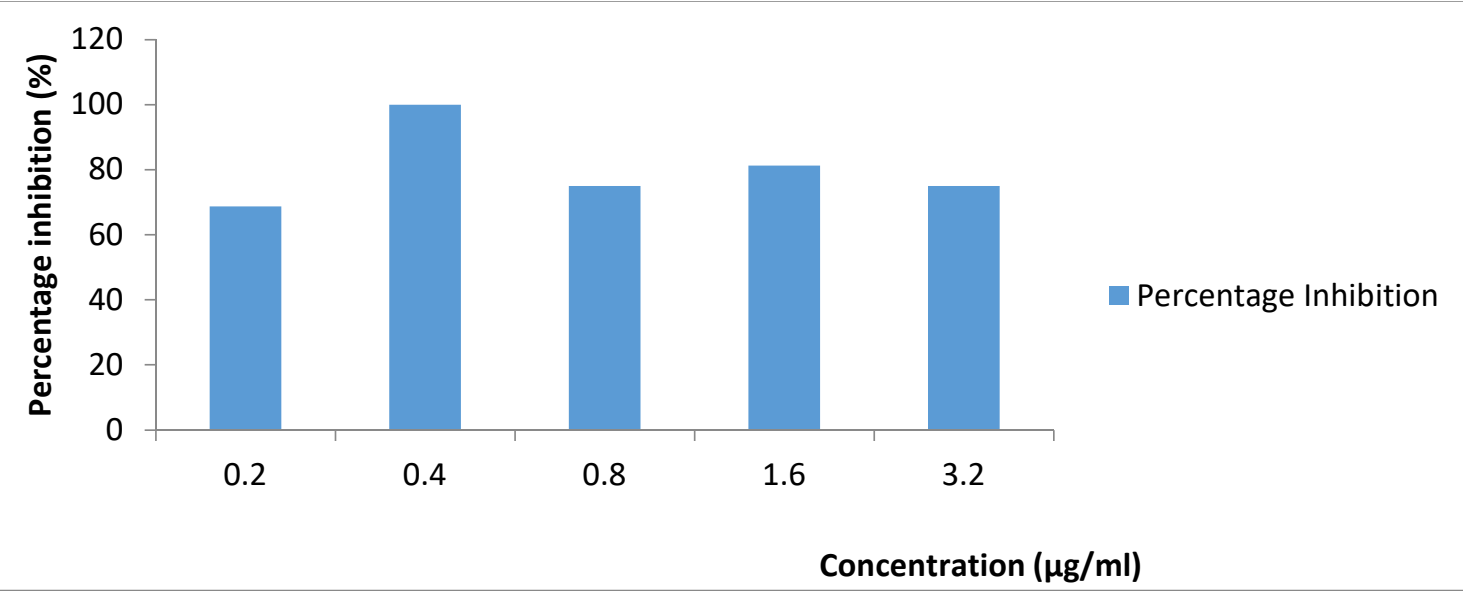

Fig 2: Percentage parasite inhibition of Plasmodium falciparum by Arthemether/lumefanthrine

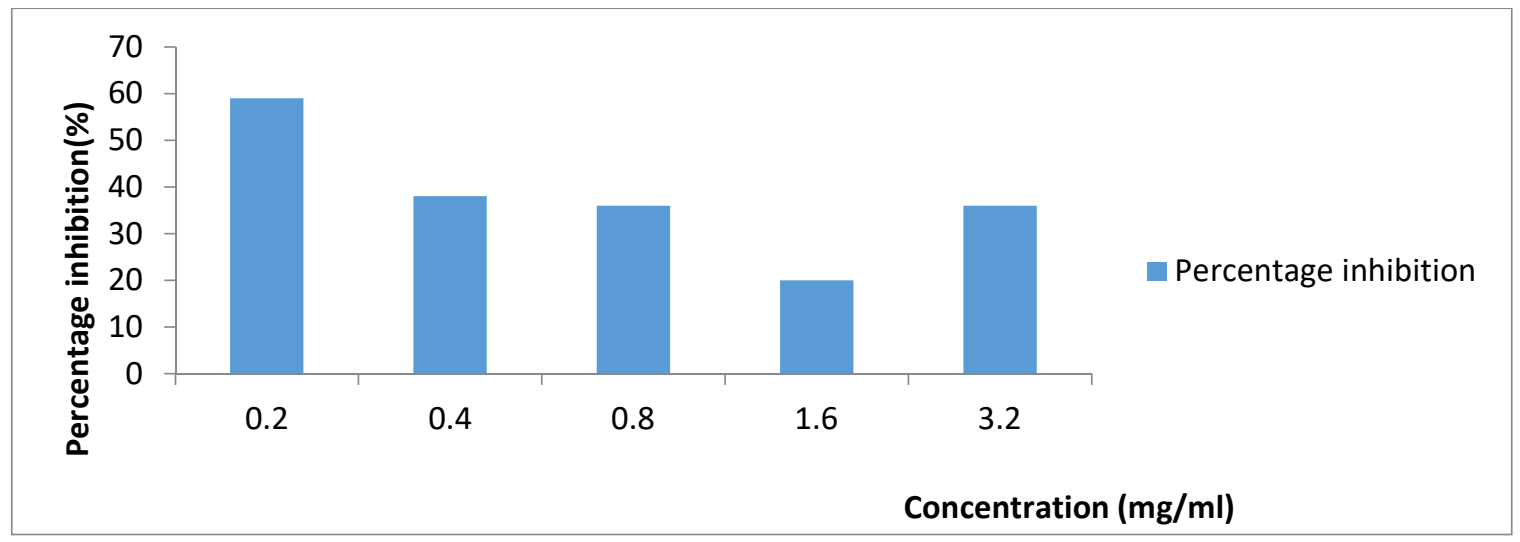

Fig 3: Percentage parasite inhibition of Plasmodium falciparum by Amodiaquine.

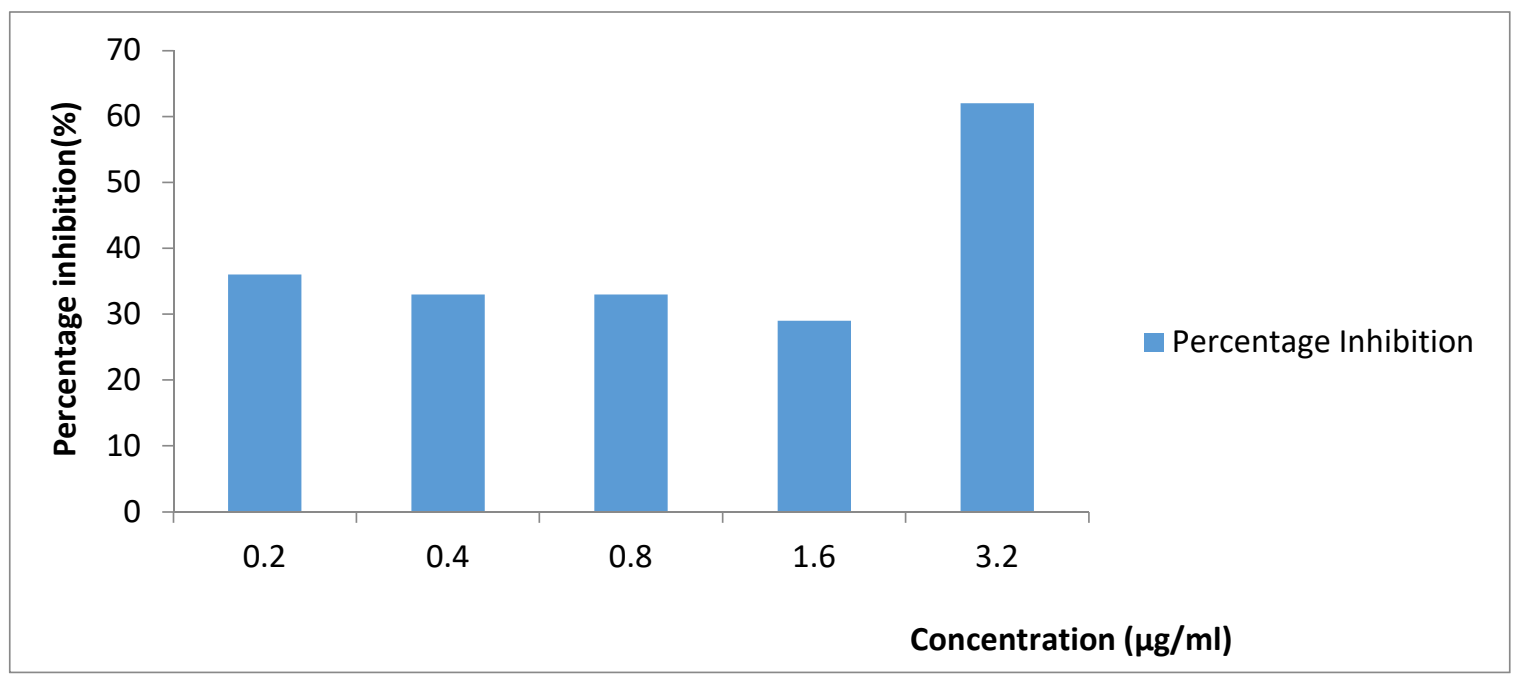

Fig 4: Percentage parasite inhibition of Plasmodium falciparum by Herbal Concoction 


\section{Discussion}

The overall prevalence of asymptomatic Plasmodium falciparum parasitaemia among school children in Zaria is $17.5 \%$. This percentage

Page | 4108 is above the $14.1 \%$ reported during a study involving children in orphanages in Zaria and Kaduna, Nigeria (Inabo and Umaru, 2011). Higher prevalence of Plasmodium falciparum infection has been reported in sub-Saharan African cities; 33.8\% in Kenya (Bousema et al., 2004) and 30\% in Uganda (Nankabirwa et al., 2013). Furthermore, studies among children in Bayelsa, Nigeria reported 63.3\% (Abah and Temple, 2015) while another research conducted in Osogbo, Nigeria reported 25.6\% (Ojurongbe et al., 2011). The high asymptomatic Plasmodium falciparum infection prevalence reported during this study among children contrasts reports from Colombia (4.24\%), Lao People's Democratic republic (6.3\%) and Ethiopia (2.28\%) (Cucunuba et al., 2008; Akiyama et al., 2016 and Lemu Golassa et al., 2015).

The low prevalence obtained during this research might be as a result of improved awareness on preventive measures against malaria within the country. Subjects recruited during this research are school children; which indicates that they need some sort of education and are acquainted with certain awareness programs in class. The dissimilarity may additionally be as a results of contrast in geographical locations like our study being conducted in Zaria, Kaduna state, Nigeria which is essentially savannah region while research conducted in Bayelsa state- a mangrove tropical rain forest; Totoro, Eastern Uganda with a tropical monsoon climate and short dry season; or additional factors like lack of proper use of insecticide treated nets in areas where high percentages were recorded, diversity in sampling season and variation in socio economic level which will account for access to propagation sites for mosquitoes. The marginally higher prevalence observed in children between the ages 6-10 years could also be attributed to immunity thanks to subsequent re-exposure to Plasmodium falciparum as observed by Bloland et al. (1999). The incidence of asymptomatic Plasmodium parasitaemia with regards to gender showed almost no difference thanks to almost an equivalent prevalence in both males and females. The association of some socio-demographic factors like age, gender and site wasn't significant statistically $(\mathrm{p}<0.005)$.

The phytochemical screening of leaf extracts of lime showed the presence of tannins, flavonoids, phlobatanins, saponins, steroids, terpenoids, cardiac glycosides and alkaloids. These findings are in agreement with a study administered in Uyo, Akwa-Ibom state, Nigeria where Citrus aurantifolia was analyzed for phytochemical constituents while testing for its antiplasmodial effects (Ette et al., 2019). It is evident that $C$. aurantifolia has been useful against malaria parasite which support its use in the treatment of malaria.

E. chlorantha (bark and leaf) which is employed for sore treatments, fevers, coughs etc by traditional healers contains saponins, alkaloids and terpenoids consistent with a study conducted in Ibadan, Nigeria and agrees with our findings (Adebiyi and Abatan 2013).

Cymbopogbon citratus was seen to have alkaloids, tannins, flavonoids and Cardiac glycosides during this study which is in conformity with Sha'a (2014) during a study carried out in Jos, Nigeria but doesn't agree totally with findings obtained from a research conducted by Ojo and Anibijuwon et al., 2010 which showed absence of cardiac glycosides and flavonoids. Leaf extracts of Magnifera indica are highly antiplasmodial in concurrence with Ohashi et al., 2018 and Bidla et al., 2004; Ibrahim et al., 2012. Wauthoz and Balde, 2007 suggested that the foremost important constituent in mango related antiparasitic activity is mangiferin having the $\mathrm{C}$ glucosyl Xanthone structure. Our findings show occurence of alkaloids, tannins, saponins, flavonoids, and terpenoids in $M$. indica which is 
in acceptance with Ohashi et al., 2018. Kimbi et al (1998) reported little or no antimalarial activity of neem and Magnifera lucida in studies carried out by them, however, Makinde and Obih (1985) outlined that boiled Page | 4109 water extract of A.indica appeared to have schizonticidal activity against chloroquine sensitive Plasmodium berghei. Hence there is a possibility that the disparity can be accounted for by strain of parasites or species where $P$. falciparum could also be sensitive to $A$. indica as revealed in this research. It isn't unusual that some plants that are usually employed in the cure of fever or malaria in certain places could also be inert or lethal in mice while being very active in vitro. There is a presence of alkaloids, steroids, tannins, saponins, flavonoids, and cardiac glycosides in $A$. indica according to this research. This agrees with Al-Hashemi and Hossain, (2016) in their research administered in Oman during which they screened the biological activities of various neem crude extracts.

Plasmodium falciparum when treated with Arthemether/Lumenfanthrine at concentrations $0.2,0.4,0.8,1.6$ and $3.2 \mathrm{mg} / \mathrm{ml}$ recorded a percentage parasite inhibition of $68.75,100,75$, 81.25 and $75 \%$ respectively. The mean parasite inhibition was $80 \%$ which indicates the effectiveness of the drug. However, it might be expected that a sustained or exponetial rise is observed in the increase in parasite inhibition by this drug, but that wasn't precisely the case during this research. With concentration $0.4 \mathrm{mg} / \mathrm{ml}$, a $100 \%$ inhibition was observed, upon increase to $0.8 \mathrm{mg} / \mathrm{ml}$ a decrease to $75 \%$ parasite inhibition occurred. Doubling of the concentration to $1.6 \mathrm{mg} / \mathrm{ml}$ yielded an $81.25 \%$ inhibition which later dropped to $75 \%$ upon increase to three $.2 \mathrm{mg} / \mathrm{ml}$. This unexpected outcome is presumably to be due to resistance to the drug, which has been a serious concern as regards the treatment of malaria. Consistent with Nosten and Brasseur (2002), the choice of those organism's resistance (or less susceptibility) to a particular drug is dependent on the concentration that the parasites are exposed to, because in a lot of cases, the mutant parasite will initially be only less susceptible, not entirely resistant. Therefore, a better concentration should eliminate them. An average parasite inhibition of $37.8 \%$ was recorded when Amodiaquine was tested on Plasmodium falciparum. An initial reduction in the percentage inhibition was recorded upon increase in concentration. However, after increase to $3.2 \mathrm{mg} / \mathrm{ml}$, there was a rise in the inhibitory rate. This pattern could also be explained as resistance by the parasite as substantiated by variety of studies that shows that there's reduced susceptibility of Plasmodium falciparum to Amodiaquine and is best utilized in combination with an Artemisinin derivative (Gupta et al., 2002 and Folarin et al., 2011). Nosten and Brasseur (2002) also corroborate these claims while stating that "resistance to Amodiaquine follows resistance to chloroquine and therefore the useful therapeutic lifetime of the mixture (Amodiaquine and Artemisinin derivative) is perhaps short". An average percentage parasite inhibition of $38.6 \%$ was recorded when Plasmodium falciparum was treated with the formulated herbal concoction. There was initially a decreased percentage parasite inhibition; however, upon increase at $1.6 \mathrm{mg} / \mathrm{ml}$, there was a pointy increase. It's speculated that this pattern could also be explained by the unknown pharmacokinetic or pharmacodynamic characteristics of the components of the herbal concoction. Furthermore, the increased parasite inhibition observed after a raise in concentration could also be attributed to a synergetic effect of the active ingredients present in the herbal concoction. This agrees with the findings of Gathirwa et al., (2008) whose research demonstrated the usefulness of mixing numerous plants to treat malaria. The discrepancy between the drug performance of Arthemether/ lumenfanthrine and herbal concoct-ion was statistically significant. 


\section{Conclusion}

The study established that a large number of children in school have asymptomatic Plasmodium falciparum infection and were harboring the parasite as confirmed by the result. This is often a sign that apparently healthy looking children have the disease and buttresses the very fact that malaria is endemic and of public health importance.

There are biologically active nutrients (phytochemicals) present in many plants locally utilized in the treatment of malaria that play several roles within the body of consumers including aiding the treatment of malaria. The phytochemical constituent in the prepared herbal concoction tend to have a complementary effect on one another i.e, in whichever plant a phytochemical constituent is lacking, another plant auguments it.

Plasmodium falciparum can be cultivated in Jatropha curcas plant extract medium with materials that are available and really affordable. Arthemether/Lumenfanthrine is the best drug against malaria parasite (Plasmodium falciparum) in this study albeit herbal medication has also been very effective.

\section{Competing Interest}

The authors declare no competing interests

\section{References}

Adebiyi, O.E., Abatan, O.M. (2013). Phytochemical and acute toxicity of ethanolic extract of Enantia chlorantha (oliv) stem bark in albino rats. Interdisciplinary Toxicology 6(3):145-151

Adesokan, A.A., Akanji, M.A. and Yakubu, M.T.(2007). Antibacterial potentials of aqueous extract of Enantiachlorantha stem bark. African Journal of Biotechnology, 6(22), 2502.
Agbaje, E.O. and Onabanjo, A.O. (1998). Analgesic and antipyretic actions of Enantia chlorantha extract insome laboratory animals. Nigerian Journal of Natural Products and Medicine, 2, 24-25. Doi:10.4314/njnpm.v2i1.11776

Bloland, P.B., Boriga, D.A., Ruebush, T.K., McCormick, J.B. and Roberts J.M. (1999). Infection in an area of intense Malaria Transmission II. Descriptive Epidemiology of malaria infection and disease among children. American Journal of Tropical Medicine and Hygiene, 60 :641-648.

Cheel, J., Theoduloz, C., Rodriguez, J. and Schmeda-Hirschmann, G. (2005). Free radical scavengers and anti-oxidants from Lemongrass (Cymbopogon citratus DC strapf). Journal ofAgricultural and Food Chemistry, 53(7), $2511-2517$

Dhar, R., Zhang, K., Talwar, G. P., Garg, S. and Kumar, N. J.(1998).Inhibition of growth and development of asexual and sexual stages of drug-sensitive and resistant strains of the human malaria parasite Plasmodium falciparum by neem (Azadirachta indica). Journal of Ethnopharmacology, 61(1), 3139. Doi:10.1016/S0378-8741(98)00012-9.

Fasola, T.R., Adeyemo, F.A., Adeniji, J.A. and Okonko, I.O. (2011). Antiviral potentials of Enantia chloranthaextracts on yellow fever virus. Nature and Science, 9(9), 99-105.

Folarin, O.A., Bustamante, C., Gbotosho, G.O., Sowunmi, A., Zalis, M.G., Oduola, A.M.J. and Happi, C.T. (2011). In vitro amodiaquine resistance and its association with mutations in pefrt and pfmdr1 genes of Plasmodium falciparum isolates from Nigeria. Acta tropica, 120(3), 224-230.

Gathirwa, J.W., Rukunga, G.M., Njagi, E.N.M., Omar, S.A., Mwitari, P.G., Guantai, A.N. and Ndiege, I.O. (2008). The in vitro 
antiplasmodial and in vivo anti-malarial efficacy of combinations of some medicinal plants used traditionally for treatment of malaria by the Meru community in Kenya. Journal of ethnopharmacology, 115(2), 223-231.

Gupta, S., Thapar,M.M., Mariga, S.T., Wernsdorfer, W.H. and Bjorkman, A. (2002). Plasmodium falciparum: in vitro interactions of artemisinin with amodiaquine, pyronaridine, and chloroquine. Experimental parasitology, 100(1), 28-35.

Harborne, J.B. (1973). Phytochemical methods; A guide to modern techniques of plant analysis. $2^{\text {nd }}$ Edition, London New York.

Ibrahim, H.A., Imam, I.A., Bello, A.M., Umar, U., Muhammad, S., Abdullahi, S.A. (2012). The potential of Nigerian medicinal Plants as Antimalarial Agent: A review. International Journal of Science and Technology 2(8). ISSN 2224-3577

Inabo, H.I. and Umaru,B.Z (2011). Studies on the incidence of asymptomatic Plasmodium infection among apparently healthy subjects in orphanages in Kaduna and Zaria, Nigeria. Bayero Journal of Pure and Applied Sciences, 4(2), 83 - 86

Kochar, D.K., Thanvi, I., Joshi, A., Agrawal, N. and Jain, N. (1999). Mortality trends in falciparum malaria- effect of gender difference and pregnancy. The Journal of the Association of Physicians of India, 47(8), 774-778.

Leite, J.R., SeabraMde, L., Maluf, E., Assolant, K., Suchecki, D., Tufik, S., Klepacz, S., Calil, H.M. and Carlini, E. (1986). Pharmacology of lemongrass (Cymbopogon citratus Strapf) III.Assessment of the eventual toxic, hypnotic and anxiolytic effects on humans.
Journal ofEthnopharmacology, 17(1), 7583.

Loy, D. E., Liu, W., Li, Y., Learn, G. H., Plenderleith, L., J.; Sundararaman, S.A., Sharp, P. M. and Hahn, B. H. (2017). Out of Africa: origins and evolution of the human malaria parasites Plasmodium falciparum and Plasmodium vivax. International Journal for Parasitology, 47 (2-3), 87-97. https://doi.org/10.1016/j.ijpara.2016.05.00 $\underline{8}$

Makinde, J.M. and Obih, P.O. (1985). Screening of Morinda lucida leaf extract for antimalarial action on Plasmodium berghei in mice. African journal of medicine and medical sciences, 14(1-2), 59-63

Mustofa, J., Sholikhah, E.N. and Wahyuono, S. (2007). In vitro and In vivo antiplasmodial activity and cytotoxicity of extracts of Phyllanthusniruri. Herbs traditionally used to treat malaria in Indonesia. Southeast Asian Journal of Tropical Medicine and Public Health, 38(4), 609-615.

Nankabirwa, J., Wandera, B., Kiwanuka, N., Staedke, S.G., Kamya, M.R.and Brooker, S.J. (2013). Asymptomatic Plasmodium Infection and Cognition among PrimarySchoolchildren in a High Malaria Transmission Setting in Uganda.American Journal of Tropical Medicine and Hygiene, 88(6), 1102-1108. doi:10.4269/a jtmh.120633

Nassar, A.S., Lasore, O.A., Ibiyemi, O. G. and Yusuf, S.O. (2014) In-Vitro Cultivation of Plasmodium falciparum in Jatropha curcas Plant Medium to Determine AntiPlasmodia Activities.Journal of Natural Sciences Research,4(16) 
Nosten, F. and Brasseur, P. (2002). Combination Therapy for malaria. The way forward. Current Opinion, 62 (9): 1315-1329.

Odugbemi, T.O., Odunayo, R., Akinsulire, I., Aibinu, E. and Fabeku, O. (2007). Medicinal Plants Useful ForMalaria Therapy in Okeigbo, Ondo State, Southwest Nigeria. African Journal of Traditional, Contemporary and Alternative Medicine, 4(2), 191-198.

Ohashi, M., Amoa-Bosompem, M., Kwofie, D. K., Agyapong, J., Adegle, R., Sakyiamah, M.M., Ayertey, F., Owusu, K.B., Tuffour, I., Atchoglo, P., Tung, H.N., Uto, T., Aboagye, F., Appiah, A. A., AppiahOpong, R., Nyarko, K.A., Anyan, K.W., Ayi, I., Boakye, D.A., Koram, A.K., Edo, D., Yamaoka, S., Shoyama, Y., Ohta, N.(2018). Invitro antiprotozoan activity and mechanisms of action of selected Ghanian medicinal plants against Trypanosoma, Leishmania and parasites. Phytotherapy Research, 1-14.

Ohno, T., Kita, M., Yamaoka, Y., Imamura, S., Yamamoto,T., Mitsufuji,S. and Imanishi, J. (2003). Antimicrobial activity of essential oils against Helicobacter pylori. Helicobacter, 8(3), 207-215

Ola, I.O., Omomowo, I.O., Aina, D.A., Majolagbe, N.O. and Oladipo, E.K.(2013). Bacteriological evaluation and antimicrobial sensitivity test of common herbal concoction in Ogbomoso metropolis. African Journal of Microbiology Research, 7(48), 5479-5483

Ojo, O.O., \& Anibijuwon, I.I. (2010) Studies on extracts of three medicinal plants of Southwestern Nigeria. Hoslundia opposita, Lantana camara and Cymbopogbon citrates. Advances in Natural and Applied Sciences, 4(1), 93-99
Ojurongbe, O., Adegbayi, A.M., Bolaji, O.S., Akindele, A.A., Adefioye, O.A., Adeyeba, O.A. (2011). Asymptomatic falciparum malaria and intestinal helminthes coinfection among school children in Osogbo, Nigeria. Journal of Research in medical sciences: the official journal of Isafahan University of Medical Sciences, 16(5), 680686.

Oladimeji, J.S. and Ojibo, S.D. (2012). Governance perceptions of informalenterprise operators in Zaria, Nigeria.American International Journal ofContemporary Research, 2(10): 150-159

Olasehinde, G.I., Ojurongbe,O., Adeyeba, A.O., Fagade, O.E., Valecha,N., Ayanda.I.O., and Egwari, L.O. (2014). In vitro studies on the sensitivity pattern of Plasmodium falciparum to anti-malarial drugs and local herbal extracts. Malaria journal, 13(1), 1-7.

Openshaw, K. (2000). A review of Jatropha curcas: an oil plant of unfulfilled promise. Biomass and bioenergy, 19(1), 1-15.

Rich, S. M., Leendertz, F.H., Xu, G., Lebreton, M., Djoko, C. F., Aminake, M. N., Takang, E. E., Diffo, J. L. D., Pike, B. L., Rosenthal, B. M., Formenty, P., Boesch, C., Ayala, F. J. and Wolfe, N. D. (2009). "The origin of malignant malaria". Proceedings of the National Academy ofSciences,106(35), 14902-14907.

Salako, L. (2006). Reflections on malaria control and research in Nigeria.Nigerian Journal of Clinical Biomedical Research,1(1), 21-25.

Sinka, M.E., Bangs, M.J., Manguin, S., Coetzee, M., Mbogo, M.C., Hermingway, J., Patil. A.P., Temperley, W.H., Gething, W.P., Kabaira, W.C., Okara, M.R., Boeckel, T.V., Godfray, C.H.T., Harbach, R.E. and Hay, I.S. (2010). The dominant Anopheles vectors of human malaria in Africa, Europe 
and the Middle East: occurrence data, distribution maps and bionomic précis. Parasite and Vectors, 3(117)

Sofowora, A. (1993). Medicinal plants and traditional medicine in Africa. Second Edition, Spectrum Books Limited, Ibadan, Nigeria. 289pp.

Sha'a, K.K. (2014). Antiplasmodial Activity of Aqueous ad Ethanolic Extracts of Anacardium occidentale and Cymbopogbon citrates (Doctoral dissertation)

Trager, W. and Jensen, J.B. (1980). Cultivation of erythrocytic and exoerrythrocythic stages of plasmodia. In Pathology, Vector Studies, and Culture (pp.271-319). Academic Press.

Trease, G.E., and Evan, W.C (1989). Pharmacognosy. $11^{\text {th }}$ edition. Brailliar Tiridel Can. Macmillan Publishers. 